Article

\title{
Effects of Cement-Mineral Filler on Asphalt Mixture Performance under Different Aging Procedures
}

\author{
Zhenyang Fan ${ }^{1, *} \mathbb{C}$, Xuancang Wang ${ }^{1, *}$, Zhuo Zhang ${ }^{2}$ and Yi Zhang ${ }^{1}$ \\ 1 School of Highway, Chang'an University, Xi'an 710064, China \\ 2 School of Water Resources and Hydropower, Sichuan University, Chengdu 610027, China \\ * Correspondence: 2017021060@chd.edu.cn (Z.F.); wxc2005@chd.edu.cn (X.W.); Tel.: +86-029-8233-4836 (Z.F.)
}

Received: 20 August 2019; Accepted: 6 September 2019; Published: 10 September 2019

\begin{abstract}
Cement-containing mineral powder can effectively improve the moisture stability of an asphalt mixture; therefore, this study systematically summarizes the research status of cement-mineral fillers on the performance of an asphalt mixture and determines the limitations of related studies. In this study, long-term performance tests of styrene-butadiene-styrene- (SBS)-modified asphalt mixtures are designed and evaluated with different blending ratios of the cement-mineral powder under three aging conditions. Moreover, the effect of the cement-mineral composite filler on long-term performance of the asphalt mixture using different blending ratios is determined. Cement improves the high-temperature performance and water stability of asphalt mixtures, but only for certain aging conditions. Considering the regulations for the road performance of asphalt mixtures for three aging conditions, as well as long-term performance considerations, the results indicated that the mass ratio of Portland cement to mineral powder must not exceed 2:2. Low-temperature bending and splitting tensile tests confirmed that an excessive amount of cement filler will embrittle the modified asphalt mixture during long-term aging, thereby deteriorating the tensile properties. The mechanism by which the filler influences the performance of the asphalt mixture should be further studied from the perspective of microscopic and molecular dynamics.
\end{abstract}

Keywords: asphalt mixture; cement; filler; long-term performance; aging; SBS-modified asphalt

\section{Introduction}

Mineral fillers play an important role in improving the workability and stability of asphalt mixtures [1,2]. Various types of fillers have different effects on the performance of asphalt mixtures [3,4]. In recent years, the partial replacement of mineral powder by industrial waste has gained considerable research attention considering the long-term performance of asphalt pavements [5-8]. At present, the most common filler used in asphalt pavement is limestone ore [9]. In China, the Technical Specifications for Construction of Asphalt Pavements [10] stipulate that cement can be used instead of a part of the mineral powder, as a part of the filler to improve the adhesion of asphalt to acid stone, thereby improving the moisture stability. In recent years, it has become common practice to use cement instead of ore as a filler in asphalt pavements in hot and humid areas. It is also common worldwide to mix various filler materials for replacing mineral powder to improve the performance of asphalt mixtures [11-13].

Cement-mineral composite fillers improve the anti-rutting performance and moisture stability of the asphalt mixture compared to single limestone powder fillers [14]. This is mainly because the content of calcium oxide in cement is higher than that of mineral powder; therefore, its alkalinity is higher than that of mineral powder. In the preparation of an asphalt mixture, the alkaline component of cement reacts with the acidic component of asphalt to produce a substance with strong adhesion $[15,16]$. This results in strong binding of the aggregate and asphalt, thereby improving the water stability of 
the mixture. Ahmad et al. [17] studied the effects of using two types of mineral fillers on the strength of asphalt mixtures in terms of the Marshall stability and retained strength, and showed that ordinary Portland cement (OPC) and pulverized limestone have a similar effect on the Marshall stability. Thus, the use of OPC resulted in higher values of retained strength. Because unaged asphalt mixtures were used in that study, the long-term moisture stability and low-temperature crack resistance were not evaluated. Wang [18] found that the addition of cement and slaked lime can significantly improve the adsorption capacity of asphalt and improve the moisture stability of the asphalt mixture. However, the study did not consider the effect of aging on the test results, and the test data analysis tended to be qualitative. Zhi et al. [19] found that the moisture stability improvement effect of the asphalt mixture after aging under all filler combinations was reduced. However, the study primarily focused on the improvement effect of cement fillers on the moisture stability of aged asphalt mixtures.

Thus, the effect of cement fillers on the performance of asphalt mixtures after aging is still debatable, and the effect of cement-mineral composite fillers on the performance of asphalt mixtures under long-term aging has not been definitively studied. In addition, moisture damage and low-temperature shrinkage occur mostly in the upper or middle layers of asphalt pavements, which usually consist of modified asphalt. However, previous studies have focused on samples mostly made of matrix asphalt. Therefore, this knowledge gap must be addressed.

Notably, some studies have applied colloidal theory to analyze the interaction between different types of fillers and asphalt [20-23]. The effects of different fillers on the rheological properties of asphalt cement were studied with asphalt mastic as the test object [24-26]. For example, Movilla-Quesada et al. [27] used Portland cement (CEM II/A-L 32.5 R) and calcium hydroxide as two different types of filler to study the stiffness of the corresponding bituminous mixture. According to colloidal theory, when active ore powders with a large specific surface area, high degree of irregularity, and high content of alkaline components are mixed with asphalt, the rheological properties of the asphalt cement significantly change because of the chemical properties and particle packing of the ore powder [28]. The acidic component of the asphalt reacts with the ore fines so that the interface between the asphalt and the ore fines forms a strong bond [29]. Cement is a more active alkaline material, and not only has the characteristics of a mineral powder but also has a pH of 12 after silicates $C_{3} S \backslash C_{2} S$ and water in the cement are digested; on the other hand, the $\mathrm{pH}$ of general limestone ore powder is only 9 [30]. When the alkaline component of the cement reacts with the hydroxy acid in the asphalt, the resulting product has an improved adsorption performance [31]. Moreover, when the asphalt reacts with the cement, the oil content (molecular weight MW 300 to 1000) and asphaltene (MW 2000 to $10,000)$ with a low molecular weight will enter the cement due to the irregularity of cement particles and presence of large open voids. The oil content refers to the saturated fraction and aromatic fraction. At this time, the consistency of the asphalt cement is also increased, thereby improving the temperature stability and water stability of the asphalt concrete.

Colloidal theory can be applied to analyze the interaction mechanism between different fillers and asphalt. However, the asphalt binder is a mix of asphalt and filler, and asphalt concrete is a mixture of asphalt after the dry mixing of filler and aggregate. That is, in the asphalt mortar, the filler is directly dispersed uniformly in asphalt to form a colloidal dispersion. In the asphalt mixture, the filler (e.g., cement) is not directly and uniformly dispersed in the asphalt but is present in the contact surface of the asphalt and aggregate and is dispersed in the structural asphalt film. Considering the difference in the production mode and filler distribution between asphalt cement and asphalt concrete, the influence of the filler on the rheological properties of asphalt cement cannot directly reflect its influence on the performance of the asphalt mixture. Therefore, when studying the effect of the filler on the mixture properties, the mixture must be selected as the test sample.

Based on the current research status, this study designed a performance test for styrene-butadiene-styrene- (SBS)-modified asphalt mixtures for three different aging procedures. The fillers were various cement-mineral powder combinations (five ratios). By analyzing the performance test results of the modified asphalt mixtures with the different cement-mineral powder 
composites under the three aging procedures, the effect of the cement-mineral composite filler with different blending ratios on the long-term performance of the asphalt mixture was determined.

\section{Test Materials and Methods}

\subsection{Raw Materials and Mix Ratio}

\subsubsection{Modified Asphalt}

In this study, Shell SBS (I-D type)-modified asphalt produced by Guangdong Xin Yue Company was used. The test results for the main performance indicators are listed in Table 1. Moreover, considering the need to analyze the performance of asphalt mixtures after aging, this study also conducted performance tests of the residue of the modified asphalt itself after three different aging procedures. The specific test results are shown in Table 1 . The three aging methods were unaged, film heating $\left(163^{\circ} \mathrm{C}, 5 \mathrm{~h}\right.$ and $\left.180^{\circ} \mathrm{C}, 10 \mathrm{~h}\right)$, and PAV pressure aging heating. The test method was based on the "Test Procedure for Highway Engineering Asphalt and Asphalt Mixture" (JTG E20-2011). The technical index requirements are listed following the requirements of "Technical Specifications for Highway Asphalt Pavement Construction" (JTG F40-2004).

Table 1. Conventional properties of modified asphalt and test results of residues after aging.

\begin{tabular}{|c|c|c|c|c|}
\hline Material & Test Item & $\begin{array}{c}\text { Test } \\
\text { Result }\end{array}$ & $\begin{array}{c}\text { Technical } \\
\text { Requirement [10] }\end{array}$ & Test Method [32] \\
\hline \multirow{9}{*}{ SBS-modified asphalt } & $\begin{array}{l}\text { Penetration }\left(25^{\circ} \mathrm{C}, 100 \mathrm{~g}, 5 \mathrm{~s}\right) \\
(0.1 \mathrm{~mm})\end{array}$ & 53 & $40-60$ & T 0604-2011 \\
\hline & Penetration index (PI) & 0.06 & $\geq 0$ & T 0604-2011 \\
\hline & Softening Point $\left({ }^{\circ} \mathrm{C}\right)$ & 87.0 & $\geq 75$ & T 0606-2011 \\
\hline & Ductility at $5^{\circ} \mathrm{C}(\mathrm{cm})$ & 33.1 & $\geq 25$ & T 0605-2011 \\
\hline & $\begin{array}{l}\text { Dynamic viscosity at } 135^{\circ} \mathrm{C} \\
(\mathrm{Pa} \mathrm{s})\end{array}$ & 2.99 & $\leq 3$ & T 0625-2011 \\
\hline & Flashpoint $\left({ }^{\circ} \mathrm{C}\right)$ & 246 & $\geq 230$ & T 0611-2011 \\
\hline & $\begin{array}{l}\text { Solubility in Trichloroethylene } \\
\text { (\% wt) }\end{array}$ & 99.89 & $\geq 99.0$ & T 0607-2011 \\
\hline & Flexible recovery at $25^{\circ} \mathrm{C}(\%)$ & 95 & $\geq 85$ & T 0603-2000 \\
\hline & $\begin{array}{l}\text { Relative density at } \\
25^{\circ} \mathrm{C}\left(\mathrm{g} / \mathrm{cm}^{3}\right)\end{array}$ & 1.034 & & T 0603-2011 \\
\hline \multirow{3}{*}{$\begin{array}{l}\text { Residue after rolling thin-film } \\
\text { oven test }\left(163^{\circ} \mathrm{C}, 5 \mathrm{~h} / 180^{\circ} \mathrm{C}, 10 \mathrm{~h}\right)\end{array}$} & $\begin{array}{c}\text { Retained penetration } \\
\left(25^{\circ} \mathrm{C}, 100 \mathrm{~g}, 5 \mathrm{~s}\right)(0.1 \mathrm{~mm})\end{array}$ & $44 / 30$ & & T 0609-2011 \\
\hline & Softening point $\left({ }^{\circ} \mathrm{C}\right)$ & $78 / 77.5$ & & T 0609-2011 \\
\hline & Ductility at $5{ }^{\circ} \mathrm{C},(\mathrm{cm})$ & $20.2 / 0.4$ & & T 0609-2011 \\
\hline \multirow{3}{*}{$\begin{array}{c}\text { Residue after pressurized aged } \\
\text { vessel (PAV) Test }\end{array}$} & $\begin{array}{l}\text { Penetration }\left(25^{\circ} \mathrm{C}, 100 \mathrm{~g}, 5 \mathrm{~s}\right) \\
(0.1 \mathrm{~mm})\end{array}$ & 27 & & T 0630-2011 \\
\hline & Softening point $\left({ }^{\circ} \mathrm{C}\right)$ & 73 & & T 0630-2011 \\
\hline & $\begin{array}{l}\text { Ductility at } 5^{\circ} \mathrm{C}, \\
5 \mathrm{~cm} / \mathrm{min}(\mathrm{cm})\end{array}$ & 4.9 & & T 0630-2011 \\
\hline
\end{tabular}

\subsubsection{Aggregate}

The aggregates were selected from the limestone specification aggregates and machine sand produced by the Da Ding Shan Stone Field in He Yuan, Guangdong Province. The performance indices of the coarse aggregates and mechanical sand can be seen in Tables 2 and 3 . The screening results of the four single-grade aggregates are shown in Table 4 . The evaluation method of adhesion with SBS-modified asphalt in Table 2 refers to the test method (T 0616) of "Test Procedure for Highway Engineering Asphalt and Asphalt Mixture" [32]. 
Table 2. Properties of coarse mineral aggregate.

\begin{tabular}{ccccc}
\hline Test Item & $\mathbf{1 0 - 2 0 ~} \mathbf{~ m m}$ & $\mathbf{5 - 1 0 ~} \mathbf{~ m}$ & $\mathbf{3 - 5} \mathbf{~ m m}$ & $\begin{array}{c}\text { Technical } \\
\text { Requirement [10] }\end{array}$ \\
\cline { 2 - 4 } & Test Result & Test Result & Test Result & $\leq 22$ \\
\hline Crushing value (\%) & 20.7 & $/$ & $/$ & $\leq 28$ \\
\hline Los Angeles abrasion loss (\%) & 21.8 & $/$ & $/$ & $\geq 2.50$ \\
\hline Apparent specific density & 2.746 & 2.747 & 2.747 & $\leq 3.0$ \\
\hline Water absorption ratio (\%) & 0.33 & 0.38 & 0.46 & $\leq 1$ \\
\hline Particle content (<0.075 mm) & 0.1 & 0.2 & 0.5 & $\leq 15$ \\
\hline Content of the needle chip granules (\%) & 5.2 & 4.3 & $/$ & $\geq 5$ \\
\hline
\end{tabular}

Table 3. Properties of fine mineral aggregate.

\begin{tabular}{ccc}
\hline \multirow{2}{*}{ Test Item } & $\mathbf{0 - 3} \mathbf{~ m m}$ & Technical Requirement [10] \\
\cline { 2 - 2 } & Test Result & Rech \\
\hline Apparent specific density & 2.734 & $\geq 2.50$ \\
Sand equivalent $(\%)$ & 85 & $\geq 60$ \\
Particle content $(<0.075 \mathrm{~mm})(\%)$ & 0.5 & $\leq 1$ \\
\hline
\end{tabular}

Table 4. Gradations of mineral aggregate.

\begin{tabular}{ccccc}
\hline \multirow{2}{*}{ Size (mm) } & \multicolumn{4}{c}{ Passing Ratio (\%) } \\
\cline { 2 - 5 } & $\mathbf{1 0 - 2 0} \mathbf{~ m m}$ & $\mathbf{5 - 1 0} \mathbf{~ m m}$ & $\mathbf{3} \mathbf{5} \mathbf{~ m m}$ & $\mathbf{0 - 3} \mathbf{~ m m}$ (Machine Sand) \\
\hline 26.5 & 100.0 & 100.0 & 100.0 & 100.0 \\
19 & 94.2 & 100.0 & 100.0 & 100.0 \\
16 & 65.0 & 100.0 & 100.0 & 100.0 \\
13.2 & 25.8 & 100.0 & 100.0 & 100.0 \\
9.5 & 0.6 & 95.1 & 100.0 & 100.0 \\
4.75 & 0.1 & 0.4 & 95.4 & 100.0 \\
2.36 & 0.1 & 0.0 & 0.1 & 86.5 \\
1.18 & 0.1 & 0.0 & 0.1 & 57.3 \\
0.6 & 0.1 & 0.0 & 0.1 & 41.4 \\
0.3 & 0.1 & 0.0 & 0.1 & 22.3 \\
0.15 & 0.1 & 0.0 & 0.1 & 14.0 \\
0.075 & 0.1 & 0.0 & 0.1 & 11.3 \\
\hline
\end{tabular}

2.1.3. Filler

The packing was made of limestone ore powder and Portland cement (P.O 32.5 R), produced by Hui Xin Stone Powder Processing Plant, Hui Cheng District, Huizhou City. For the limestone used in processing the mineral powder, the content of $\mathrm{CaCO}_{3}$ is about $95 \%-97 \%$. Its appearance is shown in Figure 1. The main performance indices are shown in Table 5.

Table 5. Basic properties of mineral powder and Portland cement.

\begin{tabular}{ccccccc}
\hline \multirow{2}{*}{ Property } & $\begin{array}{c}\text { Apparent } \\
\text { Density }\left(\mathbf{g} / \mathbf{c m}^{3}\right)\end{array}$ & $\begin{array}{c}\text { Specific Surface } \\
\text { Area }\left(\mathbf{c m}^{2} / \mathbf{g}\right)\end{array}$ & $\begin{array}{c}\text { Water } \\
\text { Content } \mathbf{( \% )}\end{array}$ & \multicolumn{2}{c}{ Thin Degree (\% Passing Ratio) } \\
\cline { 5 - 7 } & & & $\mathbf{0 . 3} \mathbf{~ m m}$ & $\mathbf{0 . 1 5} \mathbf{~ m m}$ & $\mathbf{0 . 0 7 5} \mathbf{~ m m}$ \\
\hline Mineral Power & 2.742 & 3468 & 0.1 & 100 & 98.0 & 93.5 \\
Portland Cement (32.5 R) & 2.985 & 3689 & & 100 & 98.5 & 97.6 \\
\hline
\end{tabular}




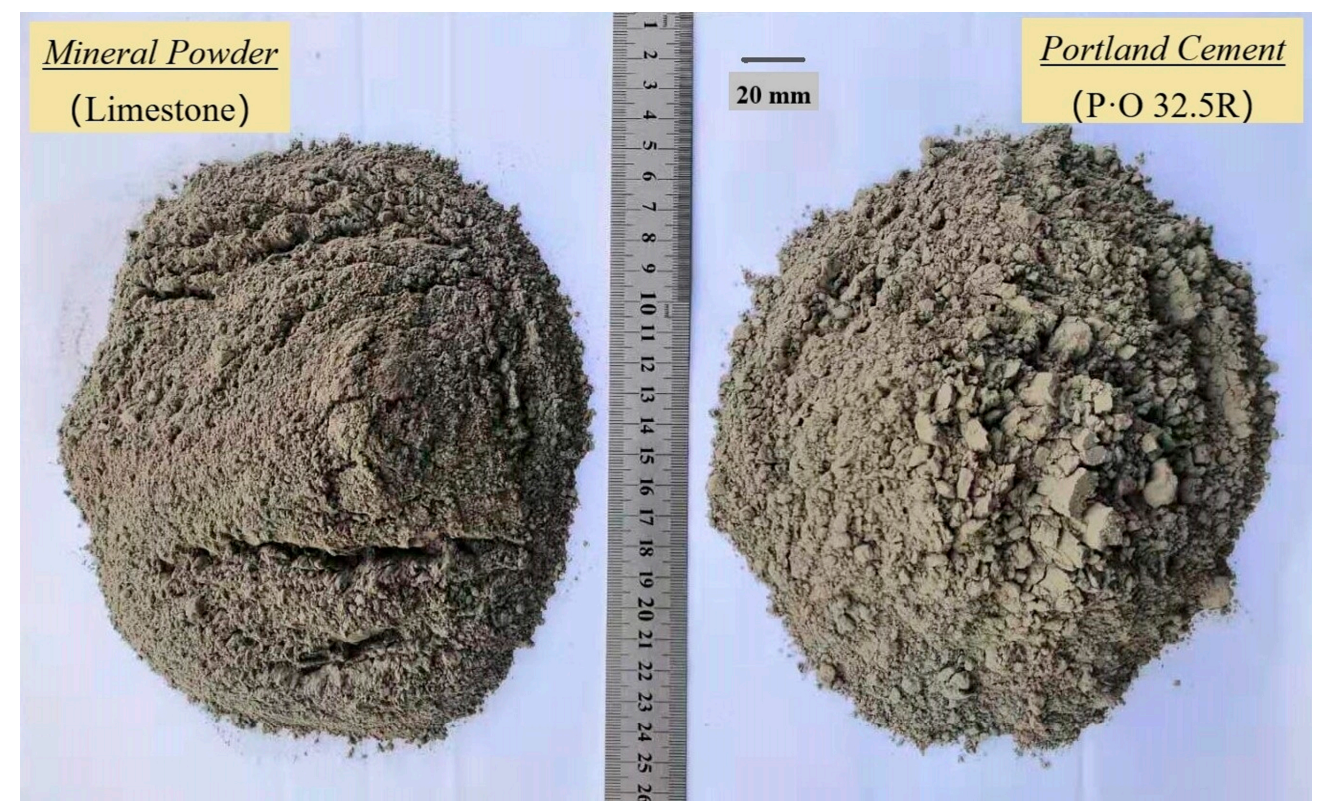

Figure 1. The appearance of the two types of fillers.

\subsubsection{Synthetic Grading of Mineral Materials}

In this study, the AC-20 C asphalt mixture with modified asphalt, commonly used in the hot and humid regions of southern China, was used as the test object. The synthetic gradation of the mineral materials is shown in Table 6.

Table 6. Grading composition and technical requirements of AC-20 asphalt mixture.

\begin{tabular}{|c|c|c|c|c|c|c|c|c|c|c|c|c|}
\hline \multirow{2}{*}{ Gradation Range } & \multicolumn{12}{|c|}{ Passing Ratio (\%) } \\
\hline & 26.5 & 19 & 16 & 13.2 & 9.5 & 4.75 & 2.36 & 1.18 & 0.6 & 0.3 & 0.15 & 0.075 \\
\hline Upper limit & 100 & 100 & 92 & 85 & 75 & 53 & 44 & 32 & 24 & 18 & 4 & 7 \\
\hline Lower limit & 100 & 95 & 78 & 65 & 48 & 23 & 16 & 12 & 10 & 7 & 8 & 3 \\
\hline Synthetic grading & 100 & 97.7 & 86 & 70.3 & 59 & 33.8 & 23.8 & 16.8 & 13 & 8.4 & 6.4 & 5.6 \\
\hline
\end{tabular}

\subsubsection{Mixture Ratio}

Using the above raw materials, the target mix ratio of the AC-20 asphalt mixture used to design the mineral gradation curve was as follows: $10-20 \mathrm{~mm}$ : $5-10 \mathrm{~mm}$ : $3-5 \mathrm{~mm}$ : $0-3 \mathrm{~mm}$ : mineral powder $=40: 25: 7: 24: 4$; the bitumen/aggregate ratio $(\%)$ was $4.3 \%$.

\subsection{Test Design and Method}

In this study, the above mixture ratio was used to prepare the mixture, and the total proportion of the filler used was $4 \%$. To compare and analyze the influence of different proportions of cement-mineral filler on the long-term performance of the asphalt mixture, this study designed combinations of two types of fillers with five ratios; note that the total mass ratio after the combination of the two fillers was not changed. For convenience, the mass ratio of Portland cement and mineral powder was recorded as $\mathrm{M}_{\mathrm{PC}} / \mathrm{M}_{\mathrm{MP}}$. Hence, the five combination ratios were 0:4, 1:3, 2:2, 3:1, and 4:0, and the content of the corresponding cement substitute mineral powder was $0 \%, 25 \%, 50 \%, 75 \%$, and $100 \%$, respectively.

The asphalt mixture mixed in each proportion was tested for road performance under three different aging procedures. The three aging procedures were no aging, short-term aging, and long-term aging, as per the China Highway Engineering Asphalt and Asphalt Mixture Test Regulations (T 0734-2000) methods. Naturally, the three aging procedures correspond to different degrees of aging. The long-term aging procedure is the deepest, followed by the short-term aging procedure [33]. 
The short-term aging test piece was compacted after ventilating the loose asphalt mixture at $135^{\circ} \mathrm{C}$ for $4 \mathrm{~h}$. The long-term aging involved ventilation of the test piece that was compacted after short-term aging in a constant-temperature oven at $85{ }^{\circ} \mathrm{C}$ for $5 \mathrm{~d}$. The specific research process is shown in Figure 2.

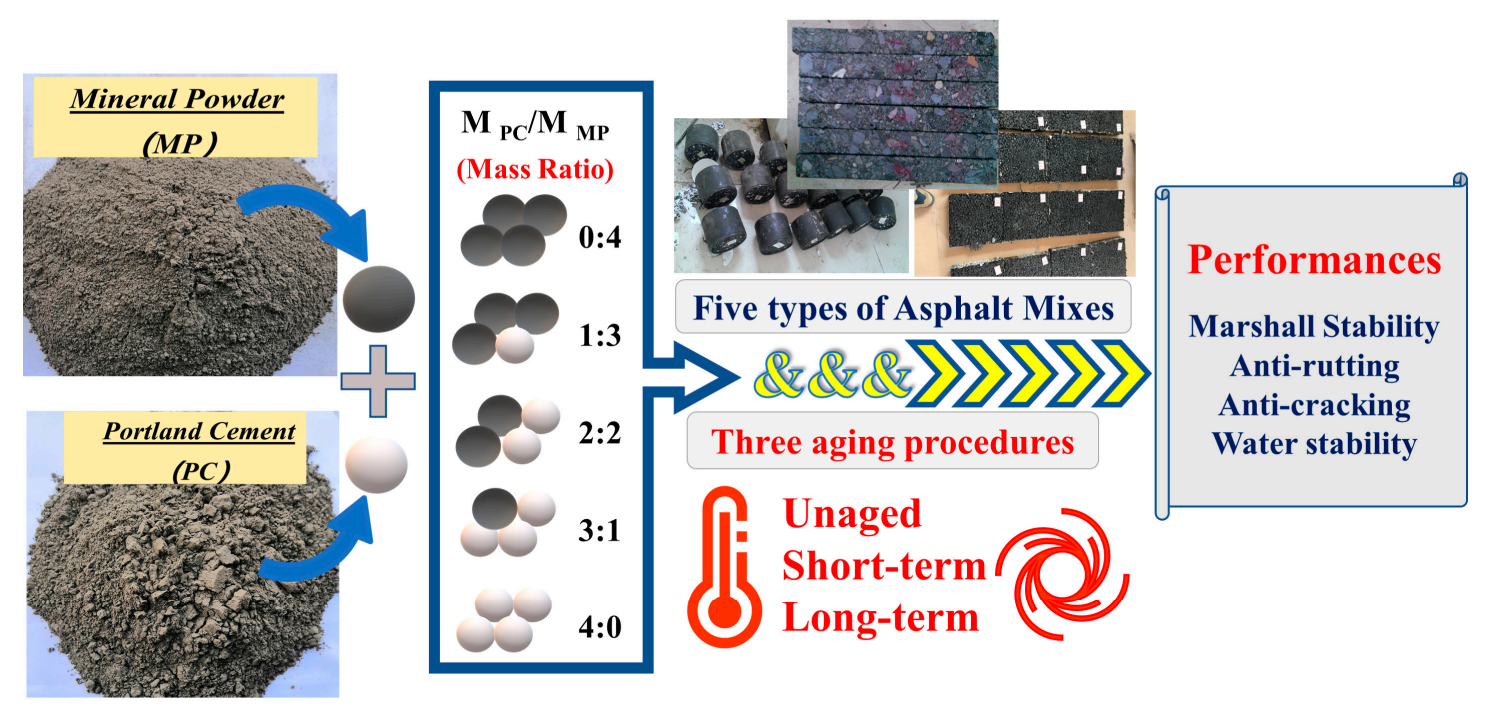

Figure 2. Schematic diagram of experimental protocol.

\subsubsection{Dynamic Stability Tests}

Rutting refers to the permanent deformation of an asphalt surface accumulated in the wheel path. It is primarily the result of repeated traffic loading cycles. The parameters selected in this study for rutting were loading of $0.7 \pm 0.05 \mathrm{MPa}$, a temperature of $70^{\circ} \mathrm{C}$, a sample size of $300 \times 300 \times 50 \mathrm{~mm}$, and a loading rate of $42 \pm 1$ times $/ \mathrm{min}$. The time period of 45-60 min was selected for calculating the dynamic stability.

\subsubsection{Immersion Marshall Stability Test}

The conditioned samples were kept in $60^{\circ} \mathrm{C}$ water for $48 \mathrm{~h}$, followed by stability tests on the control sample and conditioned samples. At the same time, the volume index, in terms of the degree of compaction and void ratio of the Marshall test piece, was measured.

\subsubsection{Low-Temperature Bending Test}

A low-temperature bending test was used to evaluate the mechanical properties of the asphalt mixture for bending and failure rates at specified temperatures and loading rates. To evaluate the low-temperature tensile properties, the sample size was $250 \times 30 \times 35 \mathrm{~mm}$, the test temperature was $-10^{\circ} \mathrm{C}$, and loading rate was $50 \mathrm{~mm} / \mathrm{min}$. A low-temperature bending test was carried out on five groups for three different aging grades, and the bending strength, maximum bending strain, and bending stiffness modulus of each specimen was obtained.

\subsubsection{Freeze-Thaw Splitting Tests}

The conditioned samples were kept at $-18{ }^{\circ} \mathrm{C} \pm 2{ }^{\circ} \mathrm{C}$ for $16 \pm 1 \mathrm{~h}$ with $10 \mathrm{~mL}$ water. Subsequently, the samples were placed in $25^{\circ} \mathrm{C} \pm 0.5^{\circ} \mathrm{C}$ water for more than $2 \mathrm{~h}$. Loading of $50 \mathrm{~mm} / \mathrm{min}$ was applied to the control and conditioned samples. The tensile strength values $\left(R_{T 1}\right.$ and $\left.R_{T 2}\right)$ and freeze-thaw splitting tensile strength ratio (TSR) before and after freezing and thawing were obtained, and the water stability for different aging degrees of each mixture was evaluated according to the value of TSR.

Using the above results, the road performance of the asphalt mixture for different cement-mineral filler systems and long-term performance change after aging were analyzed. 


\section{Results and Discussion}

\subsection{High-Temperature Anti-Rutting Performance}

For the modified asphalt mixture, the rutting test results under the conventional $60{ }^{\circ} \mathrm{C}$ test conditions tended to be high, resulting in a low degree of discrimination between the test results and high-temperature stability performance [34,35]. However, for asphalt mixtures, aging will inevitably lead to an increase in dynamic stability and high-temperature stability. Therefore, this study used the short-time-aged test piece for the $70^{\circ} \mathrm{C}$ rutting test for five types of filler combinations to analyze the effect of adding cement on the high-temperature stability of the asphalt mixture. The test results are summarized in Figure 3.

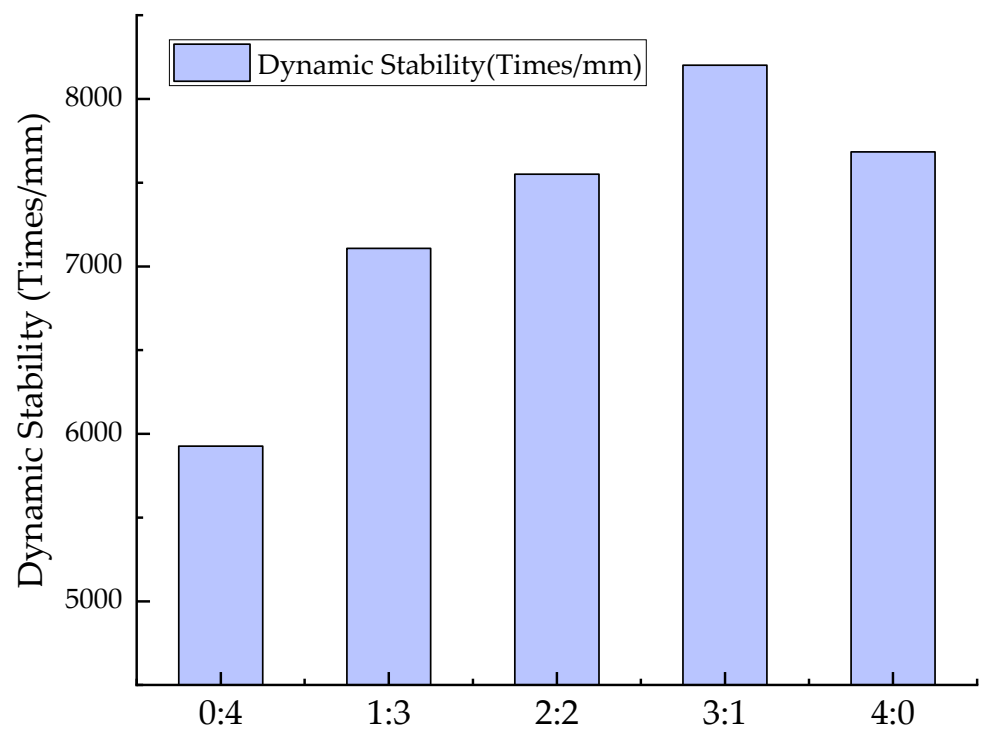

Figure 3. High-temperature stability test at $70^{\circ} \mathrm{C}$.

With an increase in cement content, the high-temperature stability of the modified asphalt mixture showed an overall increasing trend. That is, adding cement as a filler helped to increase the high-temperature stability of the asphalt mixture, which is consistent with previous experimental results. When the ratio of $\mathrm{M}_{\mathrm{PC}} / \mathrm{M}_{\mathrm{MP}}$ was 3:1, the dynamic stability reached its highest value. When the ratio of $\mathrm{M}_{\mathrm{PC}} / \mathrm{M}_{\mathrm{MP}}$ was 4:0, that is, after the cement completely replaces the mineral powder, the dynamic stability exhibited a decreasing trend. This implies that the addition of cement can significantly improve the high-temperature stability of the mixture up to a certain concentration; however, because the filler uses cement, it no longer achieves the best high-temperature stability.

\subsection{Immersion Marshall Test Results}

To comprehensively investigate the influence of the cement filler on the volumetric parameters of the asphalt mixture, this study measured the index and corresponding stability from asphalt mixture specimens for different cement/mineral ratios by the Marshall test [10,32]. The results are summarized in Table 7. 
Table 7. Volumetric parameter and Marshall test results.

\begin{tabular}{ccccccc}
\hline $\mathbf{M}_{\mathbf{P C}} / \mathbf{M}_{\mathbf{M P}}$ & $\begin{array}{c}\text { Bulk Relative } \\
\text { Density }\end{array}$ & $\begin{array}{c}\text { Void } \\
\text { Volume (\%) }\end{array}$ & $\begin{array}{c}\text { Voids in Mineral } \\
\text { Aggregate (\%) }\end{array}$ & $\begin{array}{c}\text { Voids Filled } \\
\text { with Asphalt (\%) }\end{array}$ & $\begin{array}{c}\text { Marshall } \\
\text { Stability (k N) }\end{array}$ & $\begin{array}{c}\text { Flow Value } \\
\mathbf{( 0 . 1} \mathbf{~ m m})\end{array}$ \\
\hline 0:4 & 2.545 & 4.3 & 13.5 & 68.5 & 16.28 & 49 \\
$1: 3$ & 2.549 & 4.5 & 14.1 & 68.6 & 15.11 & 41 \\
$2: 2$ & 2.552 & 4.9 & 14.7 & 66.7 & 13.80 & 41 \\
$3: 1$ & 2.558 & 4.8 & 13.9 & 65.5 & 15.96 & 48 \\
$4: 0$ & 2.577 & 4.8 & 14.2 & 66.1 & 13.78 & 41 \\
\hline
\end{tabular}

From the volume index of the Marshall test piece, as the cement replacement ratio increased, the measured relative density of the asphalt mixture increased gradually, the void ratio and mineral gap ratio decreased gradually, and the asphalt saturation increased gradually. Because Portland cement has a higher density compared to limestone ore powder, incrementally increasing the cement content will inevitably lead to an increase in the density of the asphalt mixture. Because the filler accounts for a relatively small proportion of the total mass of the mixture, the change in the proportion of cement blending had little effect on the relative density of the overall mixture. From the test results, changing $\mathrm{M}_{\mathrm{PC}} / \mathrm{M}_{\mathrm{MP}}$ did not significantly change the void ratio, mineral gap ratio, and asphalt saturation of the molded specimens, and the variation range was also small. This proves that the cement, when substituted for mineral powder, had no significant effect on the volumetric parameters of the asphalt mixture after compaction.

For the design of the asphalt mixture proportion, the Chinese standard uses the water-immersed Marshall test to evaluate the water stability of the asphalt mixture, and the residual stability ratio $\mathrm{MS}_{0}$ is used as the evaluation index. The results of the residual stability test of the asphalt mixture for different aging degrees in this study are summarized in Table 8.

Table 8. Residual stability ratio $\left(\mathrm{MS}_{0}\right)$ in immersed Marshall test for different aging degrees (\%).

\begin{tabular}{ccccc}
\hline $\mathbf{M}_{\mathbf{P C}} / \mathbf{M}_{\mathbf{M P}}$ & Unaged (\%) & Requirement (\%) & Short-Term Aged (\%) & Long-Term Aged (\%) \\
\hline $0: 4$ & 87.8 & & 81.3 & 78.3 \\
$1: 3$ & 94.1 & $\nless 85$ & 87.4 & 80.3 \\
$2: 2$ & 97.4 & & 90.7 & 82.6 \\
$3: 1$ & 95.3 & 87.9 & 83.8 \\
$4: 0$ & 96.0 & 85.9 & 82.1 \\
\hline$\triangle \mathrm{MS}_{0}$ & 9.6 & 9.4 & 5.5 \\
\hline
\end{tabular}

With the addition of cement, the residual stability of the asphalt mixture was improved; however, when the cement blending ratio was in the range of $50 \%-75 \%$, the residual stability reached a maximum. To compare and analyze the improvement effect of the cement filler on the water stability of the asphalt mixture for different aging degrees, the difference $\Delta \mathrm{MS}_{0}$ between the maximum and minimum values of residual stability in the same test group was calculated. By comparing the three aging levels of $\Delta \mathrm{MS}_{0}$, we found that after aging, the improvement in water stability due to the cement filler decreased. The improvement effect of the cement filler on water stability was $42 \%$ lower than that for the non-aging condition. To more clearly analyze the variation of residual stability for different aging degrees, the test results are plotted in Figure 4. 




Figure 4. Residual stability for three aging degrees.

\subsection{Low-Temperature Crack Resistance}

For the low-temperature crack resistance of asphalt mixtures, the maximum bending tensile strain of a trabecular beam specimen is generally evaluated when it is destroyed at $-10^{\circ} \mathrm{C}$ [36]. The specific test results are shown in Figure 5. Among them, Figure 5a reflects the influence of the cement content on the bending strength of the specimen when it is damaged. The maximum bending strain of the specimen when it is damaged is shown in Figure $5 b$, and the bending stiffness modulus of the specimen when it is damaged is shown in Figure $5 \mathrm{c}$. The plots for each parameter provide test results for three different aging conditions.

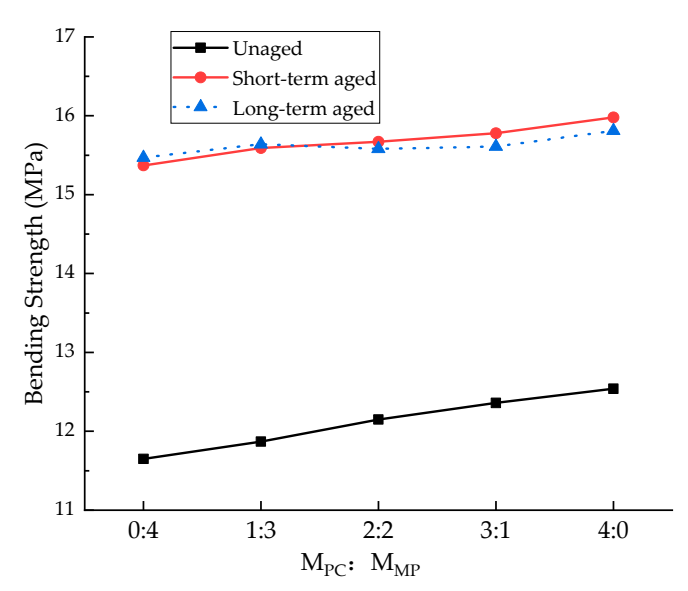

(a) Bending strength at damage, $\mathrm{R}_{\mathrm{B}}(\mathrm{MPa})$

Figure 5. Cont. 


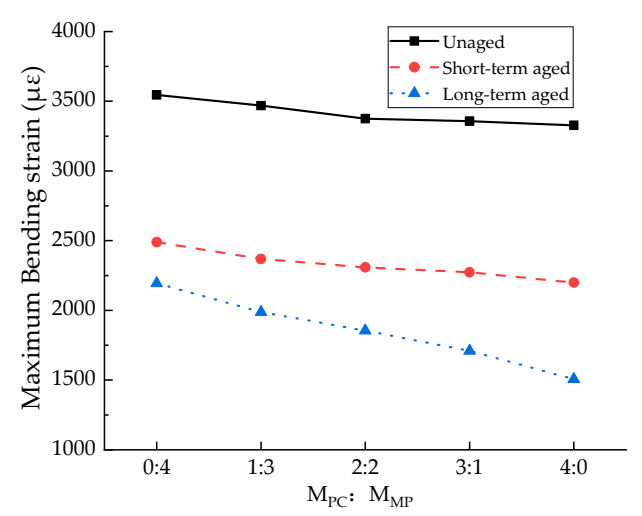

(b) Maximum bending strain at damage, $\varepsilon$ в $(\mu \varepsilon)$



(c) Bending stiffness modulus at damage, $\mathrm{S}_{\mathrm{B}}(\mathrm{MPa})$

Figure 5. Low-temperature bending test results of asphalt mixture for different aging conditions.

The test results demonstrate that with increasing $\mathrm{M}_{\mathrm{PC}} / \mathrm{M}_{\mathrm{MP}}$, the bending strength and bending stiffness modulus of the trabeculae specimens increased. Meanwhile, with increasing $M_{P C} / M_{M P}$, the maximum bending strain at damage is reduced. As for the bending strength index of the modified asphalt mixture, the influence of cement content on the unaged specimens exhibited an increasing trend, while that on the aged specimens was not considerable. The influence of the cement filler on the bending strength of the modified asphalt mixture will decrease with increasing aging degree. Figure $5 \mathrm{~b}$ shows that the test results of the unaged specimens varied gradually with increasing $\mathrm{M}_{\mathrm{PC}} / \mathrm{M}_{\mathrm{MP}}$. In the long-term aging test group, this curve exhibited a high slope and the maximum bending strain $\varepsilon_{B}$ declined considerably. Therefore, the addition of cement would considerably decrease the maximum bending tensile strain for a damaged specimen, which would become more evident with prolonged aging. Figure $5 \mathrm{c}$ shows that the bending stiffness modulus increased with the cement content and varied more with prolonged aging.

The low-temperature bending tests demonstrate that the low-temperature cracking resistance of asphalt mixtures with no aging or a small degree of aging varies slightly with an increase in the cement content, which is consistent with existing research results. However, when the asphalt mixture undergoes severe aging, adding cement will make the asphalt mixture brittle to a certain extent, thus reducing the low-temperature cracking resistance of the asphalt mixture. 


\subsection{Moisture Stability}

Freeze-thaw split and water immersion tests are important for evaluating the water stability of asphalt mixtures. In this study, the freeze-thaw splitting strength ratio and the immersion water loss rate were used as the evaluation indices for analyzing the water stability of the asphalt mixture. The specific test results are shown in Figure 6. Among them, Figure $6 \mathrm{a}-\mathrm{c}$ reflects the results of the freeze-thaw splitting test for three different aging conditions. The results of each set include the splitting strength before and after freezing and thawing $\left(R_{T 1}\right.$ and $\left.R_{T 2}\right)$ as well as the TSR.

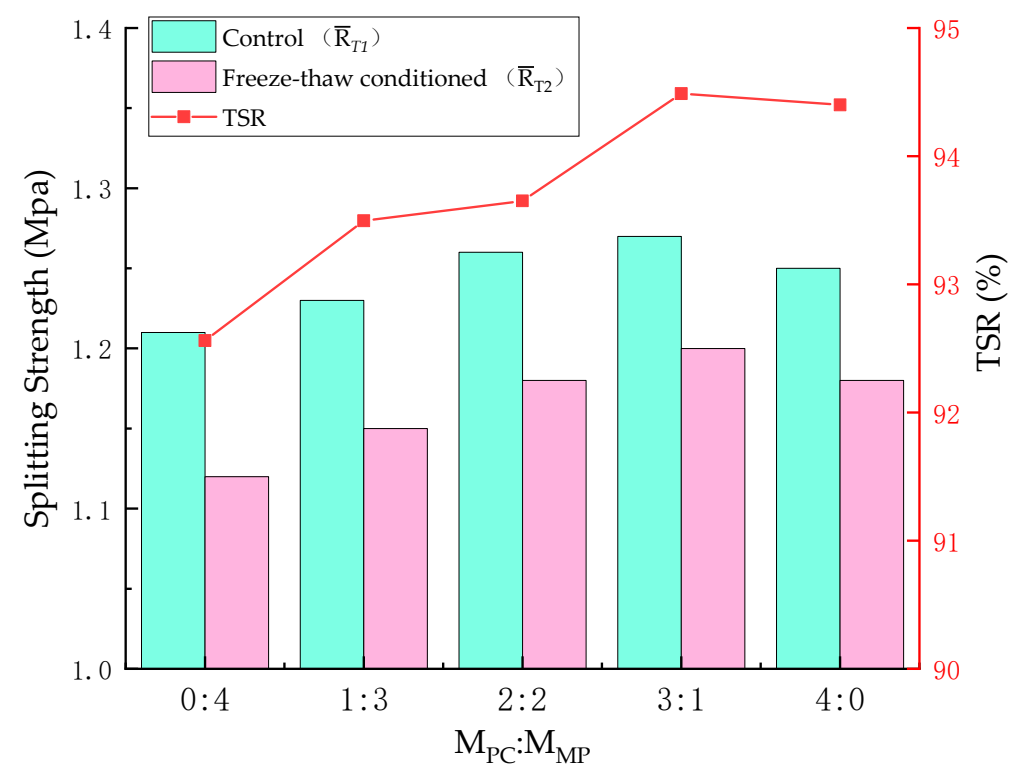

(a) Unaged test group



(b) Short-term-aged test group

Figure 6. Cont. 


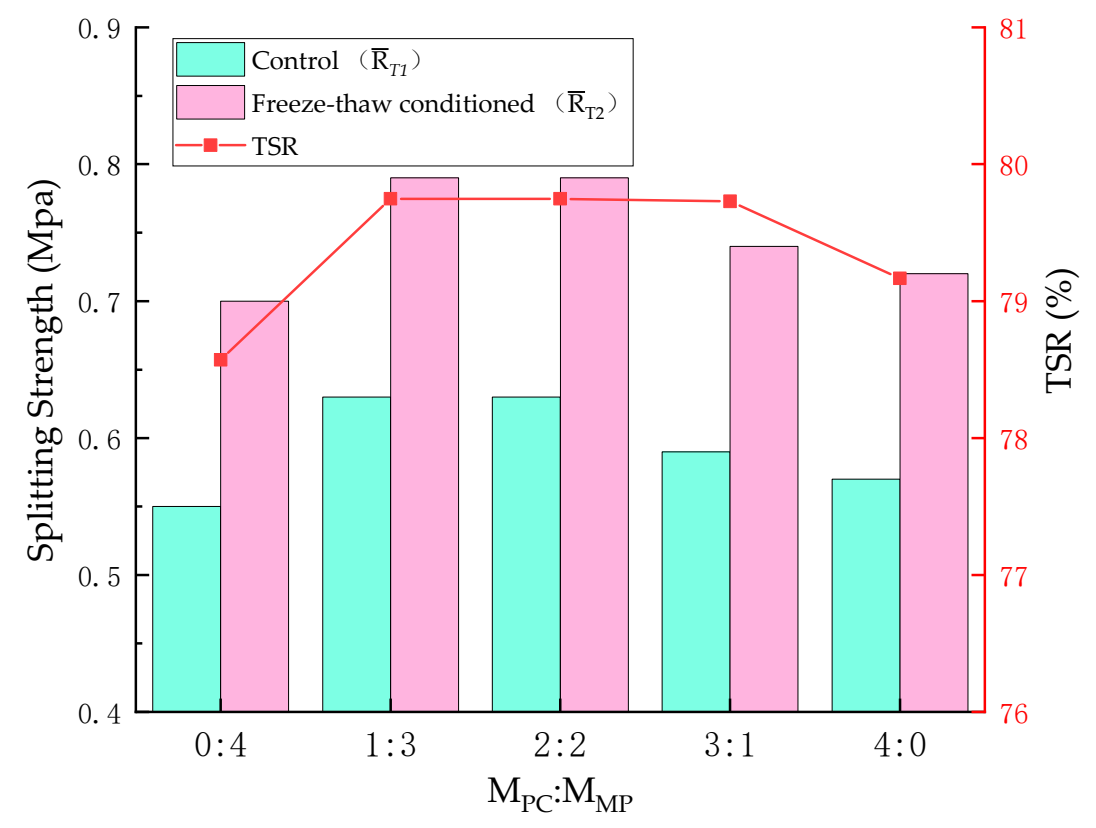

(c) Long-term-aged test group

Figure 6. Results of the freeze-thaw splitting test of asphalt mixture under different aging conditions.

The freeze-thaw splitting strength ratio TSR serves as an evaluation index for the water stability of the asphalt mixture. The results of the TSR test indicate that the cement substitute mineral powder can improve the water stability of the asphalt mixture; however, its degree of influence is different for different aging conditions. Among them, TSR reached a maximum value when $\mathrm{M}_{\mathrm{PC}} / \mathrm{M}_{\mathrm{MP}}$ was 3:1 in the unaged and short-term aging test groups. In the long-term aging test group, there was no difference between $\mathrm{M}_{\mathrm{PC}} / \mathrm{M}_{\mathrm{MP}}$ powder in the range of 1:3 to 3:1. Simultaneously, TSR decreased when cement completely replaced the mineral powder. From the results for the long-term water stability of the mixture, $\mathrm{M}_{\mathrm{PC}} / \mathrm{M}_{\mathrm{MP}}$ must not exceed 3:1.

The splitting tensile strength represents the breaking strength of the Marshall specimen when subjected to indirect stretching. Figure 6a shows that the splitting tensile strengths of the unaged mixture $\left(R_{T 1}\right.$ and $\left.R_{T 2}\right)$ reached the maximum value when $\mathrm{M}_{\mathrm{PC}} / \mathrm{M}_{\mathrm{MP}}$ was 3:1. Figure $6 \mathrm{~b}, \mathrm{c}$ show that the splitting tensile strengths $R_{T 1}$ and $R_{T 2}$ after aging reached the maximum value when $\mathrm{M}_{\mathrm{PC}} / \mathrm{M}_{\mathrm{MP}}$ was 1:3. It has been corroborated that the aging of the mixture will make it hard and brittle. In this test, with the increase in aging time, the cement content increased, reducing the indirect tensile strength of the asphalt mixture and further aggravating the embrittlement of the mixture. In conclusion, combined with the test results in Figure $6 c, \mathrm{M}_{\mathrm{PC}} / \mathrm{M}_{\mathrm{MP}}$ must not exceed 2:2.

\subsection{Mechanical Property}

Asphalt pavement structures are subjected to driving load, while asphalt mixtures experience the alternating action of pressure and tension. In an engineer's calculation of a pavement structure, the tensile fatigue failure of the asphalt surface layer is an ultimate failure state. Therefore, analysis of the mechanical properties of asphalt mixtures must be based on their tensile properties. In this study, the effects of different cement-mineral filler systems on the mechanical properties of asphalt mixtures were analyzed using two indices: bending stiffness modulus in the low-temperature bending test and indirect tensile strength in the freeze-thaw splitting test.

Figure $6 \mathrm{c}$ shows that the proportional increase of cement content with the aging level will increase the bending stiffness modulus of the mixture. For the long-term aging test group, when the ratio of $\mathrm{M}_{\mathrm{PC}} / \mathrm{M}_{\mathrm{MP}}$ is higher than 2:2, the bending stiffness modulus of the specimen will increase sharply and 
directly enter the brittle failure state. Figure $6 \mathrm{c}$ shows that the splitting tensile strength of the specimens before and after freezing-thawing treatment reaches the maximum within the range of $\mathrm{M}_{\mathrm{PC}} / \mathrm{M}_{\mathrm{MP}}$ from 1:3 to 2:2, and the best resistance is obtained. Thus, for the asphalt mixture with AC-20 gradation and SBS modified asphalt, or another asphalt mixture with similar components and composition, it is suggested that the content of cement not exceed $50 \%$ when substituted for mineral powder.

\section{Conclusions}

To explore the influence of long-term road performance and mechanical properties of asphalt mixtures, this study analyzed different cement-mineral filler combinations through a series of asphalt mixture laboratory tests. Cement was selected as it can effectively improve the water stability performance of asphalt mixtures compared with mineral powder. Further, a modified asphalt mixture (AC-20) was selected as the test object for the laboratory tests. The optimal cement-mineral filler combination ratio was also recommended.

(1) Cement can improve both the high-temperature performance and water stability of asphalt mixtures; however, when the proportion of cement is continuously increased, it will adversely affect the performance of asphalt mixtures after long-term aging.

(2) Considering the various requirements for long-term road performance of asphalt mixtures for three aging conditions, this study indicated that the ratio of $\mathrm{M}_{\mathrm{PC}} / \mathrm{M}_{\mathrm{MP}}$ must not exceed 2:2. Further, the ratio must be determined after a comprehensive consideration of the mixing ratio design of the asphalt mixture and performance requirements.

(3) The results of the low-temperature bending and splitting tensile tests confirm that excessive addition of cement filler will embrittle the modified asphalt mixture during long-term aging, resulting in a decrease in tensile properties. Among these properties, the bending stiffness modulus of the long-term aging test piece in the low-temperature bending test was particularly high and increased significantly with an increasing $\mathrm{M}_{\mathrm{PC}} / \mathrm{M}_{\mathrm{MP}}$ ratio.

(4) The specific influence of the filler on the performance of the asphalt mixture should not be directly compared with the test results of the asphalt cement. The asphalt mixture should be tested as the test object. The mechanism by which the filler influences the performance of the asphalt mixture should be further studied from the perspective of microscopic and molecular dynamics.

Author Contributions: Conceptualization; writing-review and editing; visualization; project administration; experiment, Z.F.; conceptualization; experiment guidance, X.W.; investigation and software, Z.Z.; check and partial test, Y.Z.

Funding: This research received no external funding.

Conflicts of Interest: The authors declare no conflict of interest.

\section{References}

1. Kuity, A.; Jayaprakasan, S.; Das, A. Laboratory investigation on volume proportioning scheme of mineral fillers in asphalt mixture. Constr. Build. Mater. 2014, 68, 637-643. [CrossRef]

2. Shukry, N.A.M.; Hassan, N.A.; Abdullah, M.E.; Hainin, M.R.; Yusoff, N.I.M.; Jaya, R.P.; Mohamed, A. Effect of various filler types on the properties of porous asphalt mixture. In Proceedings of the IOP Conference Series: Materials Science and Engineering, Pekan, Malaysia, 1-2 March 2018; IOP Publishing: Bristol, UK, 2018; Volume 342, pp. 012-036.

3. Zemichael, B. Effect of Different Types of Filler Materials on Characteristics of Hot-Mix-Asphalt Concrete. Master's Thesis, Addis Ababa University, Addis Ababa, Ethiopia, 2007.

4. Al-Suhaibani, A.; Al-Mudaiheem, J.; Al-Fozan, F. Effect of filler type and content on properties of asphalt concrete mixes. In Effects of Aggregates and Mineral Fillers on Asphalt Mixture Performance; ASTM International: West Conshohocken, PA, USA, 1992; pp. 107-130.

5. Chen, M.; Zheng, J.; Li, F.; Wu, S.; Lin, J.; Lu, W. Thermal performances of asphalt mixtures using recycled tyre rubber as mineral filler. Road Mater. Pavement Des. 2015, 16, 379-391. [CrossRef] 
6. Tuncan, M.; Tuncan, A.; Cetin, A. The use of waste materials in asphalt concrete mixtures. Waste Manag. Res. 2003, 21, 83-92. [CrossRef] [PubMed]

7. Do, H.S.; Mun, P.H. A study on engineering characteristics of asphalt concrete using filler with recycled waste lime. Waste Manag. 2008, 28, 191-199.

8. Hu, X.; Wang, N.; Pan, P.; Bai, T. Performance evaluation of asphalt mixture using brake pad waste as mineral filler. Constr. Build. Mater. 2017, 138, 410-417. [CrossRef]

9. Huang, B.; Shu, X.; Chen, X. Effects of mineral fillers on hot-mix asphalt laboratory-measured properties. Int. J. Pavement Eng. 2007, 8, 1-9. [CrossRef]

10. Ministry of Transport of the People's Republic of China. Technical Specifications for Construction of Highway Asphalt Pavements; Highway Research Institute of China, Transport Ministry: Beijing, China, 2004; Volume A4, p. 196.

11. Wasilewska, M.; Małaszkiewicz, D.; Ignatiuk, N. Evaluation of different mineral filler aggregates for asphalt mixtures. In Proceedings of the IOP Conference Series: Materials Science and Engineering, Prague, Czech Republic, 12-16 June 2017; IOP Publishing: Bristol, UK, 2017; Volume 245.

12. Chen, M.; Lin, J.; Wu, S. Potential of recycled fine aggregates powder as filler in asphalt mixture. Constr. Build. Mater. 2011, 25, 3909-3914. [CrossRef]

13. Modarres, A.; Ramyar, H.; Ayar, P. Effect of cement kiln dust on the low-temperature durability and fatigue life of hot mix asphalt. Cold Reg. Sci. Technol. 2015, 110, 59-66. [CrossRef]

14. Wang, J.; Guo, M.; Tan, Y. Study on application of cement substituting mineral fillers in asphalt mixture. Int. J. Transp. Sci. Technol. 2018, 7, 189-198. [CrossRef]

15. Guo, M.; Tan, Y.; Yu, J.; Hou, Y.; Wang, L. A direct characterization of interfacial interaction between asphalt binder and mineral fillers by atomic force microscopy. Mater. Struct. 2017, 50, 141. [CrossRef]

16. Guo, M.; Tan, Y.; Wang, L.; Hou, Y. A state-of-the-art review on interfacial behavior between asphalt binder and mineral aggregate. Front. Struct. Civ. Eng. 2017, 12, 248-259. [CrossRef]

17. Aljassar, A.H.; Metwali, S.; Ali, M.A. Effect of filler types on Marshall stability and retained strength of asphalt concrete. Int. J. Pavement Eng. 2004, 5, 47-51. [CrossRef]

18. Wang, X.; Dai, W. Application of cement and hydraulic lime in asphalt mixture. J. Highw. Transp. Res. Dev. 2001, 4, 20-24.

19. Qiao, Z.; Zhang, Z.; Xu, G.; Liu, Y. Study on improvement effect of different materials on water stability of crushed gravel asphalt mixture. Highw. Traffic Technol. (Appl. Tech. Ed.) 2015, 11, 57-60.

20. Meng, G.; Bhasin, A.; Tan, Y. Effect of mineral fillers adsorption on rheological and chemical properties of asphalt binder. Constr. Build. Mater. 2017, 141, 152-159.

21. Lerfald, B.O.; Horvli, I. The influence of filler materials on rheology and ageing of filler-bitumen-mixes. Road Mater. Pavement Des 2011, 4, 455-469. [CrossRef]

22. Zheng, C.; Li, R.; Zou, L.; Lv, D.; Xu, Y. Effects of filler-bitumen ratio and mineral filler characteristics on the low-temperature performance of bitumen mastics. Materials 2018, 11, 1155. [CrossRef] [PubMed]

23. Rossi, C.O.; Spadafora, A.; Teltayev, B.; Izmailova, G.; Amerbayev, Y.; Bortolotti, V. Polymer modified bitumen: Rheological properties and structural characterization. Colloids Surf. A 2015, 480, 390-397. [CrossRef]

24. Chen, J.S.; Kuo, P.H.; Lin, P.S.; Huang, C.C.; Lin, K.Y. Experimental and theoretical characterization of the engineering behavior of bitumen mixed with mineral filler. Mater. Struct. 2008, 41, 1015-1024. [CrossRef]

25. Liu, G.; Yang, T.; Li, J.; Jia, Y.; Zhao, Y.; Zhang, J. Effects of aging on rheological properties of asphalt materials and asphalt-filler interaction ability. Constr. Build. Mater. 2018, 168, 501-511. [CrossRef]

26. Cardone, F.; Frigio, F.; Ferrotti, G.; Canestrari, F. Influence of mineral fillers on the rheological response of polymer-modified bitumens and mastics. J. Traffic Transp. Eng. 2015, 2, 373-381. [CrossRef]

27. Movilla-Quesada, D.; Raposeiras, A.C.; Castro-Fresno, D.; Peña-Mansilla, D. Experimental study on stiffness development of asphalt mixture containing cement and $\mathrm{Ca}(\mathrm{OH})_{2}$ as contribution filler. Mater. Des. 2015, 74, 157-163. [CrossRef]

28. Huang, S.C.; Zeng, M. Characterization of aging effect on rheological properties of asphalt-filler systems. Int. J. Pavement Eng. 2007, 8, 213-223. [CrossRef]

29. Lesueur, D.; Petit, J.; Ritter, H.-J. The mechanisms of hydrated lime modification of asphalt mixtures: A state-of-the-art review. Road Mater. Pavement Des. 2012, 14,1-16. [CrossRef]

30. Al-Hdabi, A.; Nageim, H.A.; Seton, L. Performance of gap graded cold asphalt containing cement treated filler. Constr. Build. Mater. 2014, 69, 362-369. [CrossRef] 
31. Alvarez, A.E.; Ovalles, E.; Caro, S. Assessment of the effect of mineral filler on asphalt-aggregate interfaces based on thermodynamic properties. Constr. Build. Mater. 2012, 28, 599-606. [CrossRef]

32. Ministry of Transport of the People's Republic of China. Specifications and Test Methods of Bitumen and Bituminous Mixtures for Highway Engineering; China Communications Press: Beijing, China, 2011.

33. Airey, G.D. State of the art report on ageing test methods for bituminous pavement materials. Int. J. Pavement Eng. 2003, 4, 165-176. [CrossRef]

34. Rossi, C.O.; Caputo, P.; Loise, V.; Miriello, D.; Teltayev, B.; Angelico, R. Role of a food grade additive in the high temperature performance of modified bitumens. Colloids Surf. A 2017, 532, 618-624. [CrossRef]

35. Teltayev, B.; Aitbayev, K. Modeling of Temperature Field in Flexible Pavement. Ind. Geotech. J. 2015, 45, 371-377. [CrossRef]

36. Teltayev, B.; Radovskiy, B. Predicting thermal cracking of asphalt pavements from bitumen and mix properties. Road Mater. Pavement 2018, 19, 1832-1847. [CrossRef]

(C) 2019 by the authors. Licensee MDPI, Basel, Switzerland. This article is an open access article distributed under the terms and conditions of the Creative Commons Attribution (CC BY) license (http://creativecommons.org/licenses/by/4.0/). 